\title{
El otro muralismo en la ciudad de Chihuahua
}

\section{The other muralism in the city of Chihuahua}

\author{
Adán Erubiel Liddiard Cárdenas ${ }^{1}$ \\ Guillermo Hernández Orozco ${ }^{2}$
}

\begin{abstract}
Resumen
El presente trabajo está orientado en el contexto del muralismo en la ciudad de Chihuahua, centrándose en analizar los factores sociales y culturales que han propiciado un tipo de muralismo oficial en la ciudad, con el firme cobijo institucional, y su contraparte no oficial que convive con la comunidad en las calles y parques, restaurantes y cafés. Los resultados a través de la interpretación de las imágenes del rescate etnográfico fotográfico, nos confirman no sólo la existencia de este otro arte mural, sino la necesidad de incluirlo en el universo de lo que se denomina muralismo chihuahuense.
\end{abstract}

\begin{abstract}
Palabras clave
Artes visuales, cultura visual, factores culturales, identidad, expresión artística.
\end{abstract}

\begin{abstract}
This poster is oriented in the context of the muralism in the city of Chihuahua, focusing on analyze the social and cultural factors that have led to a type of official muralism in the city, with a strong institutional protection, and its unofficial counterpart that coexists with the community in the streets and parks, restaurants and cafes. The results through the interpretation of the images of the photographic ethnographic rescue, confirm not only the
\end{abstract}

\footnotetext{
${ }^{1}$ Adán Erubiel Liddiard Cárdenas. Universidad Autónoma de Chihuahua, México. Es Licenciado en Diseño Gráfico con Maestría en Docencia. Correo electrónico: eliddiard@hotmail.com

ID: http://orcid.org/0000-0002-6572-024X
}

2 Guillermo Hernández Orozco. Académico de la Universidad Autónoma de Chihuahua, México. Se desempeña como docente de las licenciaturas y maestría en artes, así como en el Doctorado en Educación, Artes y Humanidades. Correo electrónico: ghernand@uach.mx

ID: http://orcid.org/0000-0001-7287-8240 
RECIE. Revista Electrónica Científica de Investigación Educativa

Vol. 4, núm. 2, enero-diciembre 2019, pp. 897-907.

existence of this other mural art, but the need to include it in the universe of what is called chihuahuense muralism.

\section{Keywords}

Visual arts, visual culture, cultural factors, identity, artistic expression.

\section{Problema}

Hablar del muralismo de la ciudad de Chihuahua, ya sea por cuestiones turísticas, artísticas o meramente culturales, evoca inmediatamente a la obra de Aarón Piña Mora en el Palacio de Gobierno de dicha localidad, ya que es un trabajo icónico, insigne de este tipo de plástica en la capital del estado homónimo. Sus fragmentos más identificados, sobre todo el rostro de Miguel Hidalgo y Costilla en el presidencialmente elogiado mural El fusilamiento de la luz (Fernández y Sen Venero, 2013), son en muchas ocasiones la rúbrica de Chihuahua ante propios y extraños.

Y lo mismo sucede con otras obras murales chihuahuenses reconocidas, como los murales de Leandro Carreón en el Paraninfo de la Rectoría de la Universidad Autónoma de Chihuahua, el mural monumental La Profecía de la Raza Cósmica del mismo Piña Mora, situado en el Hotel Posada Tierra Blanca; y más actualmente las obras de Miguel Valverde en el campus 2 de la misma universidad.

Todos estos son referentes que la población chihuahuense conoce e identifica como sus murales representativos. Aquellos que llegan primero a la memoria al recomendar a los visitantes de otras partes del país y del mundo que lugares visitar y fotografiar. Y en esta condición están otras tantas obras que tuvieron la suerte de ser pintadas en las paredes de edificios gubernamentales, educativos o religiosos. Sitios en donde se les protege del daño accidental de los paseantes, de la crudeza del clima de la región, y de los diversos percances que pudieran presentarse. Hasta se invierte en su restauración en caso de ser necesario, para que el trabajo pictórico dure el mayor tiempo en la mejor condición posible. 


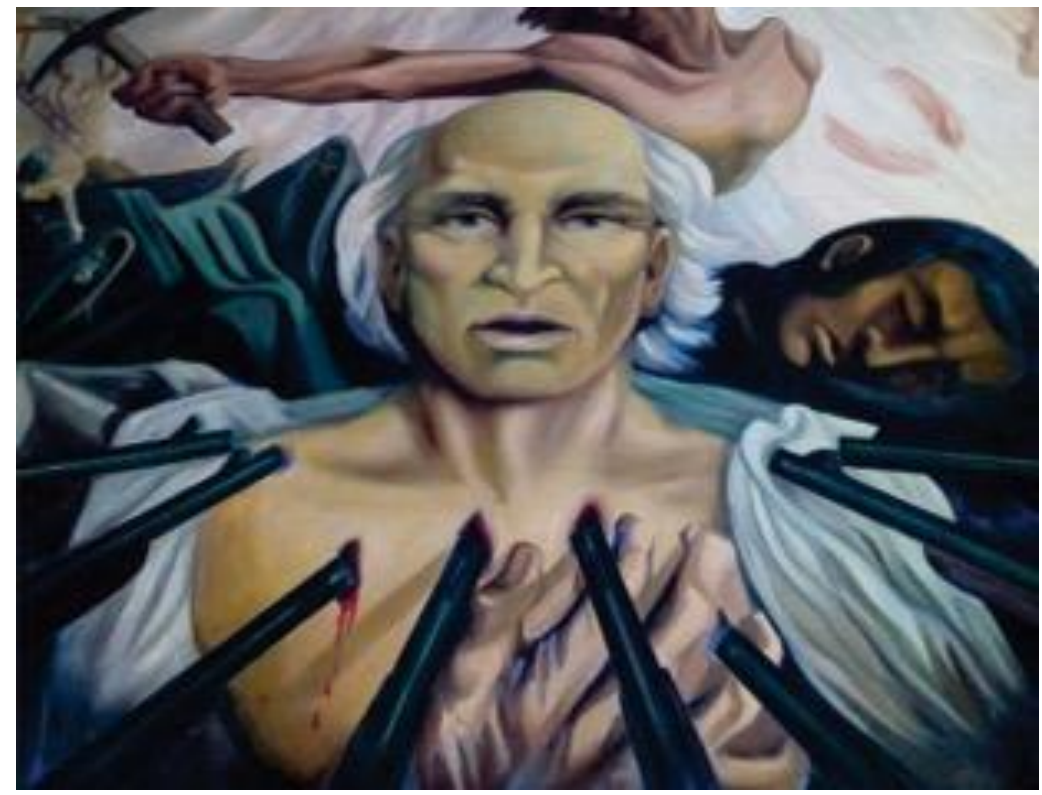

Detalle del mural El fusilamiento de la luz. Palacio de Gobierno de la ciudad de Chihuahua.

Autor muralista: Aarón Piña Mora.

Fotografía: Adán Erubiel Liddiard.

Pero al mismo tiempo existen otras obras anónimas, que no son creadas por los grandes nombres y que no están en los espacios importantes de los edificios concurridos. Murales que los libros de arte e historia local no mencionan y que difícilmente se mencionan en los salones de clase. No es difícil imaginarse entonces que su destino no es el mismo que el de su contraparte formal, y que son borrados o destruidos con gran facilidad. Al final del día son los ignorados como referencia pictórica/cultural de la comunidad, excluyéndolos de la concepción que se tiene de muralismo local reconocido.

La invisibilidad de estos murales no oficiales se aprecia como el problema, al no estar en zonas de relevancia institucional, donde la mayoría de la población pueda acudir a verlos, ya sea inclusive por el hecho de caminar por a un lado al realizar trámites personales. Sin embargo, adquieren mayormente invisibilidad hacia la apreciación de su importancia, al no valorarse como identidad y representatividad chihuahuense. Si bien pueden llegar a tener cierta relevancia a la hora de su creación entre el pequeño grupo de personas a su alrededor, su recuerdo es corto y no generalizado. 
RECIE. Revista Electrónica Científica de Investigación Educativa Vol. 4, núm. 2, enero-diciembre 2019, pp. 897-907.

\section{Objetivo}

Establecer que existe una obra pictórica mural paralela a la institucional en la ciudad de Chihuahua es significativo, es el primer paso para valorizarla y empezar a llamarla como corresponde. Pero el rescatarla de la invisibilidad mencionada, incluyéndola y adhiriéndola al universo que es el muralismo chihuahuense como un conjunto holístico medible e analizable, lo es más.

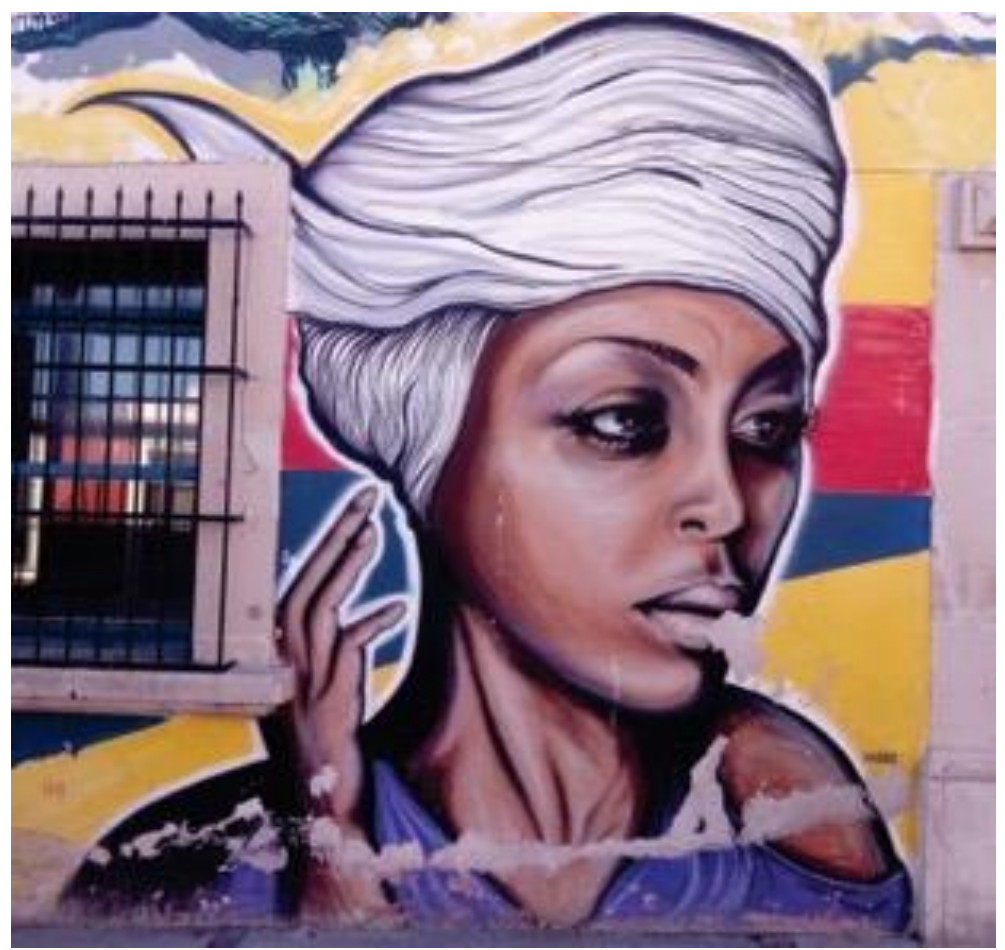

Detalle de mural exterior.

Café Momposina.

Autores muralistas: Ovrlnds Collective y Disko.

Fotografía: Adán Erubiel Liddiard.

Si bien todos los murales son observados por los transeúntes en sus espacios propios, se advierte que no todos son valorados como espejos de la realidad. Inclusive a algunos en ocasiones ni siquiera se les denomina mural. Exponer dicho análisis por este significativo canal, y darle justa dimensión, es el objetivo del presente avance de investigación. 


\section{Método}

La investigación de la cual deviene este avance es cualitativa de tipo teóricoempírico, dentro del paradigma hermenéutico-interpretativo. Sus propias características seleccionaron para su construcción un método etnográficointerpretativo de trabajo, en donde se sumerge al sujeto observador en el objeto observado dentro de una realidad compleja (Vargas, 2011).

El trabajo se lleva a cabo con las siguientes técnicas de recolección de información: 1) Observación directa en campo, visitando por zonas definidas la mayor cantidad posible de murales de la ciudad; 2) fotografía, rescatando de esta forma visual las obras visitadas; 3) historia oral, a manera de narraciones relevantes por parte de las personas que conviven de cerca con los murales; 4) entrevista semi-estructurada, obteniendo un discurso importante de primera mano de artistas muralistas o historiadores de arte locales; 5) indagación documental, necesaria al tener obras murales clave que ya no existen o por la necesidad de datos históricos en fuentes bibliográficas o periodísticas (Vargas, 2011).

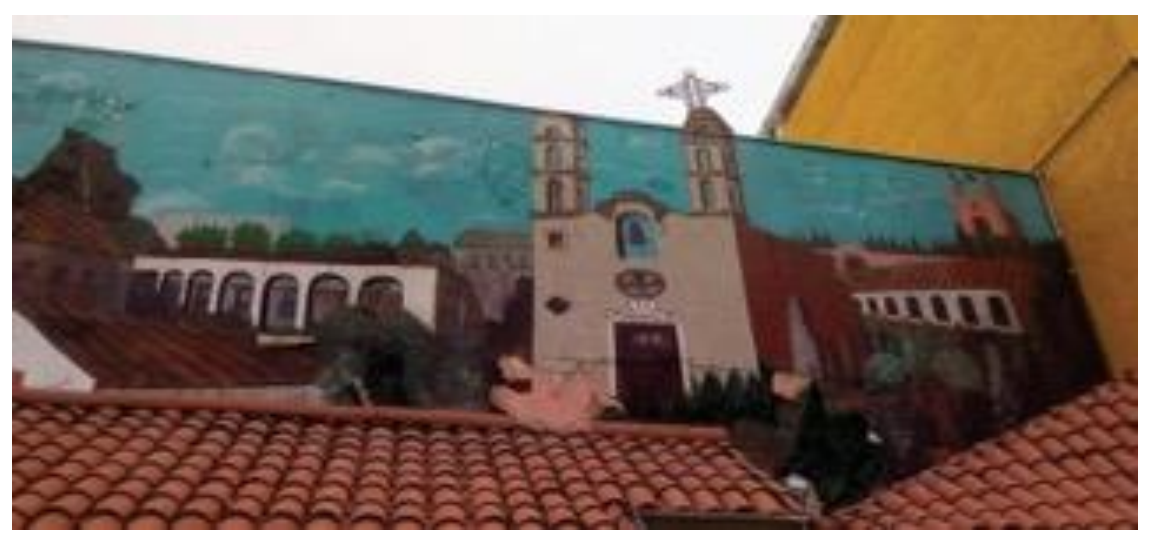

Detalle del mural La magia de mi tierra.

Restaurante Mayólica.

Autoras muralistas: Virginia Pérez y Leonor Serna García.

Fotografía: Adán Erubiel Liddiard.

Para el presente avance se escogieron seis imágenes representativas de un universo de aproximadamente 1400 fotografías tomadas hasta el momento. Los murales visitados y documentados son de diversas temáticas, tales como gubernamental, de institución educativa, religiosa, privada y urbana. El muestreo se da dentro de la técnica de la bola de nieve, siendo las mismas obras, y la conversación con las personas cercanas a estas, las que llevan al encuentro de más objetos a analizar, todo dentro de los límites geográficos de la ciudad de Chihuahua. 


\section{Tópico a discusión}

El colectivo entiende al muralismo como aquel que se da en condiciones muy específicas de oficialidad. Que lleva pompa y gala desde su concepción, ejecución y develación. Que en sus líneas y mensaje evoca a los grandes héroes y caudillos de la narración oficialista. Así, para que un mural sea mural, pareciera que debe ser una hoja arrancada de un libro de texto, con un culto al personaje y su idealización.

Mandoki (2006) relaciona el concepto de estética con reflexiones acerca del uso del poder para la asignación del término arte "verdadero". Menciona un grupo reducido de relatores de la verdad que emite su juicio de cual obra debe ser considerada arte y cual no. Al aterrizar este pensamiento al muralismo local chihuahuense, este calificativo de estético o "bello" se le da mayormente a las obras institucionales que manejan un alto carácter de solemnidad.

Pero esta cualidad de belleza sólo existe en la mente de los sujetos que observan el o los trabajos artísticos (Mandoki, 2006). No es tan absurdo pensar entonces que los prejuicios que el colectivo tiene sobre las suposiciones en cuanto a que es arte "real" afecten a la hora de asignar este calificativo. Y así, recordando que estamos inmersos en una sociedad perfilada desde la educación básica, donde sólo los actos oficiales tienen una validación a los ojos de las instituciones, va concretándose ya una idea sólida del por qué: obra oficial es igual a obra bella.

Se puede entonces hablar de una estética culta o académica, que es la que posiciona sus apreciaciones como más elevadas que las demás, o en palabras de Mandoki:

La estética académica va a especificar el status privilegiado de ciertos objetos, las obras de arte, y por contagio, el de ciertos sujetos, los estetólogos e historiadores de arte, aunque existan muchos otros objetos, sujetos y sucesos pertinentes a la estética. Y es que el estetólogo insiste en seguir trabajando en los museos, bibliotecas y salas de arte con sus libros, partituras y cuadros, para no ser turbado por los olores, sudores y ardores de la vida cotidiana (2006, pp. 1617). 


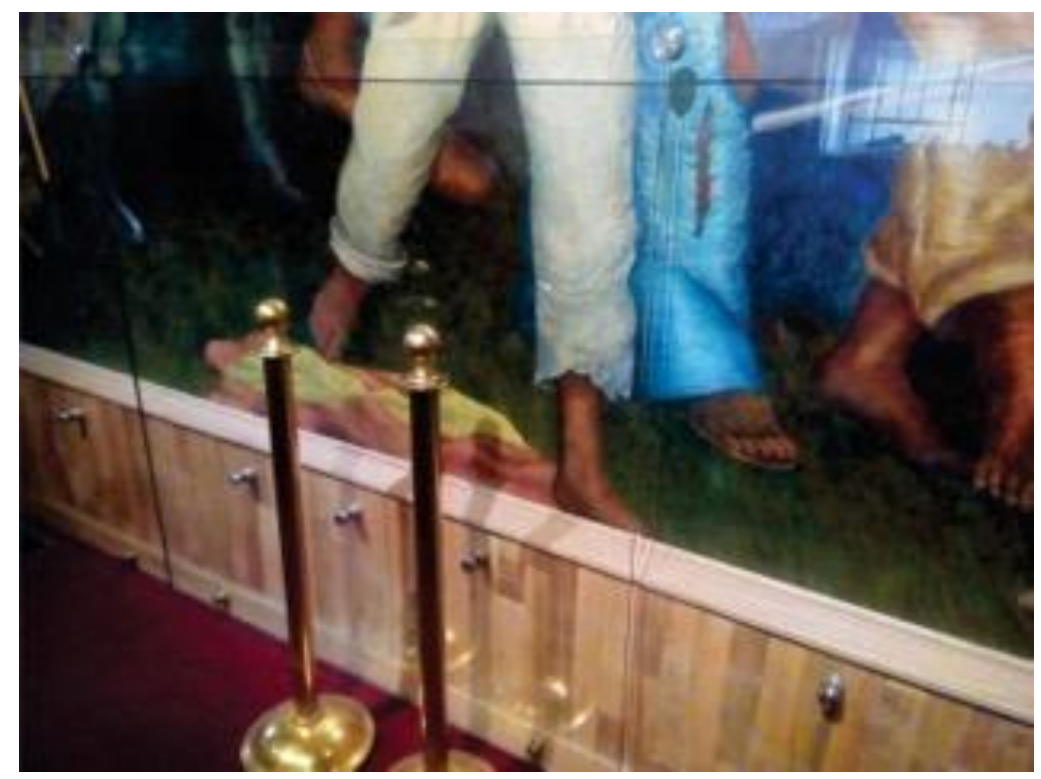

Acrílico y valla protectora en Murales.

Paraninfo de Rectoría. Universidad Autónoma de Chihuahua.

Autor muralista: Leandro Carreón.

Fotografía: Adán Erubiel Liddiard.

Ahora bien, al otro lado de la moneda se encuentra el mural no oficial, el aterrizado a su ambiente de cotidianidad, este lugar privilegiado donde Mandoki revalora los objetos que son pasados de alto por su invisibilidad en la vida diaria, tal y como enuncia:

La vinculación o separación del arte y la realidad, cuyos ecos inciden a su vez en la supuesta desvinculación entre lo estético y lo cotidiano es, pues, uno de los problemas más comunes que se han planteado los artistas, críticos y teóricos del arte. (...) El arte es y ha sido siempre un producto social y emerge directamente de la sociedad, por más elitista que sea (2006, p. 17).

Se percibe como la autora sugiere que el arte es un producto desde la sociedad y para la sociedad, y baja la condición de las obras oficiales a un ras de suelo de las obras nacidas del pópulo, sea cual sea el estrato de donde emerjan; o sube la condición de las segundas hacia el plano excelso de las primeras, según sea el punto de vista utilizado. Esto porque los artistas autores de ambos muralismos (si se pudiera continuar haciendo tal diferenciación), son hijos de la misma sociedad.

Y es este un caso de contradicción de percepción bien observado por la autora, ya que recordando lo expuesto: el concepto de estética está en 
quien observa, no en el objeto o mural per se. Esto explicaría el cómo el experto en arte logra permanecer en el museo (o en el caso del muralismo, en los edificios institucionales); ya que al ser quien emite el juicio de valoración según su apreciación, puede imponer el estatus de estético (o cultural/histórico) a la sociedad, y así no tener que extender su búsqueda de investigación a otros puntos geográficos menos "confortables" de la ciudad.

Ya en un contexto local, el muralismo de Chihuahua extrae sus ideas tanto de lo intelectual como de lo prosaico, porque el traducir los pensamientos elevados a un lenguaje común y corriente, se tiene que hacer a través de pensamientos comunes y corrientes, que sirvan de intérpretes y de enlace, propiciando el carácter educativo de cualquier obra mural.

\section{Resultados}

A través del trabajo de campo en la hasta hoy documentación casi completa de las fuentes primarias del objeto de estudio, y a la vez al contacto con el contexto que tienen en sus distintos entornos según su temática en particular, se ratifica la afirmación de que sí existe un muralismo no oficial en Chihuahua capital. Es aquel que simplemente no cumple con el estándar de solemnidad o valor histórico/académico establecido para su apreciación como tal. Que se encuentra en restaurantes o estacionamientos y no aparece en los panfletos turísticos, sino que fue creado con la encomienda de decorar el ambiente de un espacio, o de reflejar la idiosincrasia de quien vive/trabaja/circula a su alrededor. Engloba también al arte urbano en forma de mural, expresión de los jóvenes en las calles, y que tiene la frontera no muy delimitada con el mero grafiti.

Al mural oficial se le observa cuidado, limpio, con barreras físicas que delimitan hasta donde el visitante puede acercarse. Tiene a veces acrílicos o cristales protectores que lo resguardan de accidentes, y letreros de advertencia que dan la indicación de guardar la distancia prudente. Así mismo están guardias de los mismos edificios que cuidan su integridad de la misma manera que protegen los muros, el mobiliario o a quien ahí labora o transita. Es una obra que se puede observar, de una forma u otra, preservada. Ya no hablar de las placas suntuosas que ocasionalmente son colocadas al lado, con el nombre del mural, del artista, la fecha, y hasta el dato del mecenas, o como se le denomina hoy, patrocinador. 


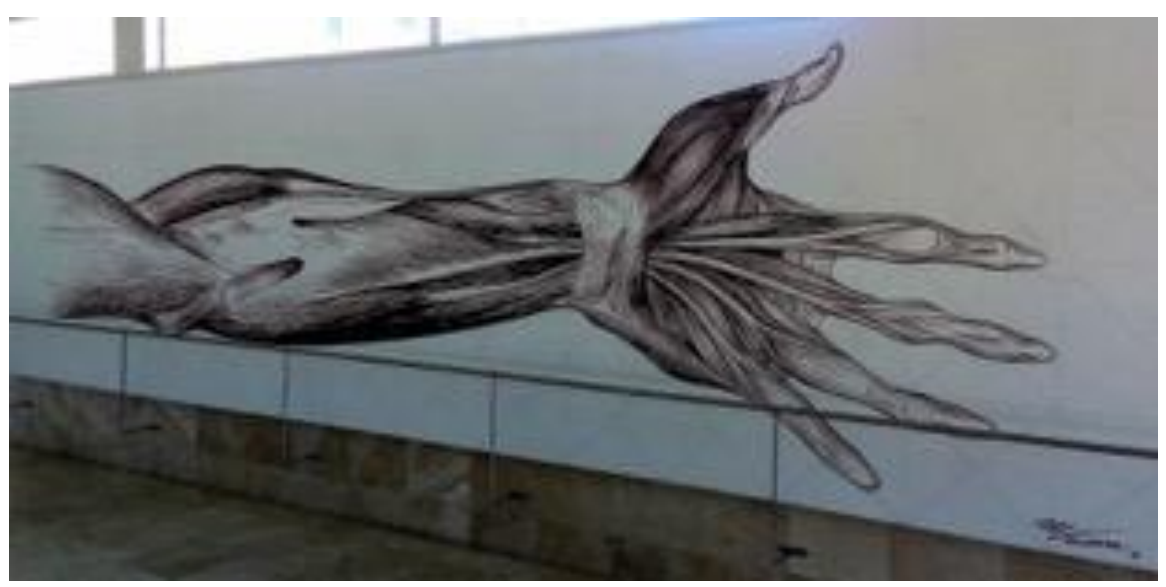

Tubo protector en el Mural de la Facultad de Medicina y Ciencias Biomédicas. Universidad Autónoma de Chihuahua.

Autor muralista: Miguel Valverde.

Fotografía: Adán Erubiel Liddiard.

Por otro lado está el mural que surge de necesidades no tan institucionales, sin un cobijo estructurado. Ese que de nacimiento tiene ya una marca de efímero, y que lucha contra el clima adverso en la intemperie y contra el mal trato de los transeúntes. Luis Safa, muralista chihuahuense, menciona sobre esto:

Hablar de los murales de Chihuahua (...), colectivos y artistas, le han dado mucho a la ciudad en cuanto a espacios y creo que eso es muy valioso. Habría que pensar solamente, ¿cuánto va a durar ese trabajo? Me refiero en la perdurabilidad de las piezas. Mucho de lo que te cuento fue en 2008 y ya no hay nada, el tiempo se lo come todo. Habría que luchar por elevar la calidad de la técnica para que algunas piezas duren un poco más, fomentar una conciencia histórica y desde ahí ir tejiendo algo. Tal vez no, todo es efímero y es el tiempo que vivimos, de igual forma esta interesante reflexionarlo" (L. Safa, comunicación personal, 21 de marzo del 2018).

En sí, es una situación que toda obra artística pública sufre, pero que se acentúa cuando por ejemplo no se sabe el futuro que tendrá la pared en donde se pinta, como el caso de muralistas urbanos que utilizan casas abandonadas a punto de ser demolidas, o piden permiso en estacionamientos donde el dueño cambia de parecer de un día a otro. El mural ve acrecentada su condición de efímero cuando no se tiene seguridad ni siquiera del sustrato que se utiliza. Se puede distinguir entonces un abismo de diferencia entre el tiempo que va a ser apreciado un mural oficial y un no oficial. 
Aunque hay que añadir que en el trabajo de campo se observaron varios casos que se pueden llamar intermedios, o sea, murales urbanos patrocinados por estancias gubernamentales, siempre bajo la estancia de concursos o festivales que fomentan distintos valores en la juventud. Estos murales suelen tener una presentación pomposa y una valoración de las autoridades positiva, pero a lo largo del tiempo vuelven a su condición de urbanos, siendo al final borrados o demolidos, y en el mejor de los casos simplemente olvidados en un rincón de una colonia de la ciudad.

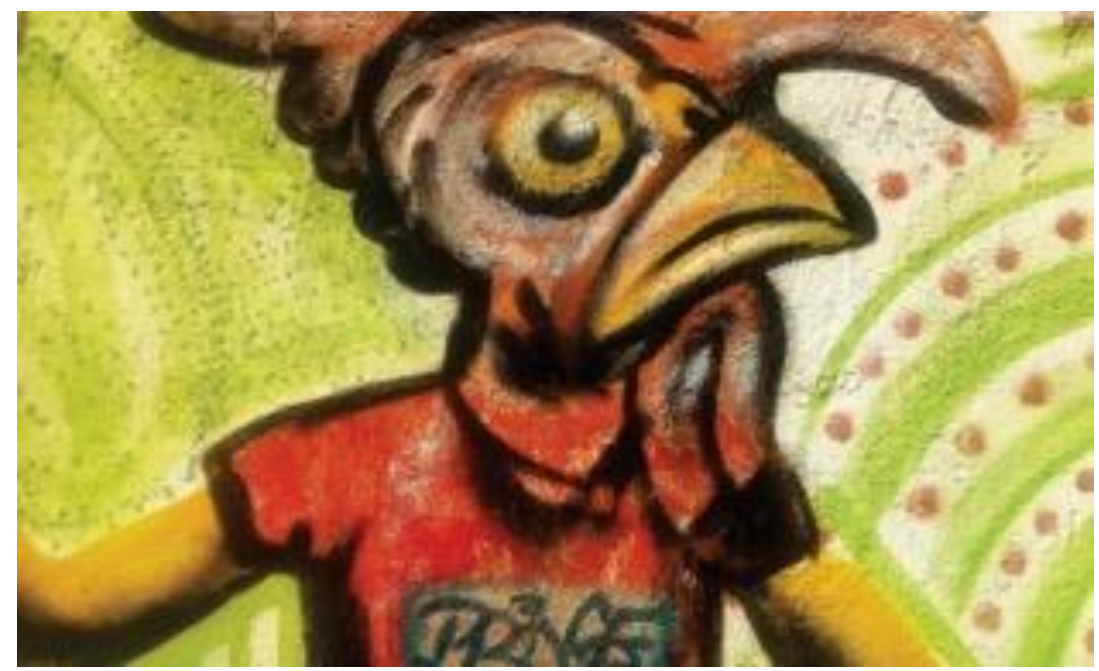

Detalle de mural urbano.

Calle Morelos Nueva y Miguel Ángel Olea.

Autor muralista: Desconocido.

Fotografía: Adán Erubiel Liddiard.

Esto lleva al tema del lugar de pertenencia, debilidad que puede transformarse en fortaleza. Y es porque en la apreciación dentro de su ambiente de cotidianidad es que estos "otros" murales encuentran revaloración. El no estar en las paredes de edificios renombrados, o en espacios demasiado solemnes, es como las obras pictóricas públicas hacen identidad, como se vuelven uno con los habitantes. Efímeras o no, se les confiere el estatus de manifestación social propia, de pertenencia. Estos murales se apropian del sitio que los vio nacer y lo hacen suyo. Dan otra visión de la sociedad, con contenido educativo igual de válido que cualquier otro. Hacen replantearse si únicamente el mensaje oficial debe representar a la comunidad. 
Y es que estas obras no oficiales tienen significado y significancia; primero, por contar con los atributos físicos necesarios para llamarse mural; y segundo, por ser una expresión del artista hacia lo que lo rodea, a su propia identidad y la de los demás, con simbolismos que evocan rincones del consiente colectivo. Es necesario entonces construir un pensamiento de reconciliación entre ambos muralismos, el oficial y el no oficial, el culto y el vulgar (tomando en cuenta que la raíz de la palabra vulgar viene de vulgo, el común de la gente), en una visión de esperanza y comprensión. Recordar que el arte es en sí un rostro más de lo cotidiano, de lo prosaico. Que las grandes ideas devienen del diario existir, en solitario o en conjunto.

En resumen, el muralismo de la ciudad de Chihuahua se enmarca en una dualidad: la pertenencia a lo oficial o a lo no oficial, esta es una realidad. Cualquiera de estas particularidades por sí solas no son negativas, son sólo una variante más que se visualiza en casi todos los aspectos de la vida, por la institucionalización o no de los actos académicos, profesionales, etc., de las personas. El problema radica cuando sólo el carácter oficial es el que pretende otorgar la validación y la apreciación de belleza comunitaria. Es en este camino en donde transita el "otro" muralismo de la ciudad de Chihuahua, rompiendo esquemas día a día, persona a persona.

\section{Referencias}

Fernández, C. A. y Sen Venero, M. I. (2013). Los murales del Palacio de Gobierno de Chihuahua. Chihuahua, México: Carlos Alberto Fernández Baca y María Isabel Sen Venero.

Mandoki, K. (2006). Estética cotidiana y juegos de la cultura. Prosaica uno. México: Siglo XXI - Conaculta.

Vargas, X. (2011). ¿Cómo hacer investigación cualitativa? Una guía práctica para saber qué es la investigación en general y cómo hacerla, con énfasis en las etapas de la investigación cualitativa. Zapopán, México: Etxeta. 
RECIE. Revista Electrónica Científica de Investigación Educativa Vol. 4, núm. 2, enero-diciembre 2019, pp. 897-907. 